(c) American Dairy Science Association, 2006.

\title{
Effects of Inbreeding in the Dam on Dystocia and Stillbirths in US Holsteins
}

\author{
V. Adamec, ${ }^{*}$ B. G. Cassell,† E. P. Smith, $\neq$ and R. E. Pearson† \\ *Department of Statistics and Operational Research, Mendel University of Agriculture and Forestry, \\ 61300 Brno, Czech Republic \\ †Department of Dairy Science, Virginia Polytechnic Institute and State University, Blacksburg 24061-0315 \\ ‡Department of Statistics, Virginia Polytechnic Institute and State University, Blacksburg 24061-0439
}

\section{ABSTRACT}

Dystocia scores were recorded by producers on 120,434 Holsteins (218,213 records) from 1985 through 1996; dystocia scores 3 to 5 were coded as difficult births. Stillbirths were recorded for deaths within the first $48 \mathrm{~h}$ after birth. Data were restricted to registered cows for pedigree completeness, and inbreeding coefficients were calculated using 5-generation pedigrees. Computational restrictions required that subsets of the data be created by choosing herds at random but using all records from selected herds. Effects of inbreeding in the dam were estimated in a sire-maternal grandsire (of the calf) threshold model using Gibbs sampling. The model included fixed effects of calf sex and inbreeding of the dam and random effects of herd-year-season of birth, additive genetic, and residual effects. First, second, and third parities were analyzed separately. Solutions for sex of calf and inbreeding from different parities were converted to expected change in probability of dystocia or stillbirth per $1 \%$ increase in inbreeding. Inbreeding effects were largest for first-parity cows giving birth to male calves at a $0.42 \%$ increase in probability of dystocia/ $1 \%$ increase in inbreeding. Effects of inbreeding for firstparity dams giving birth to female calves were smaller, $0.30 \% / 1 \%$ increase in inbreeding. Incidence of stillbirths increased 0.25 and $0.20 \%$ for male and female calves $/ 1 \%$ increase in inbreeding for first parity births. Effects of inbreeding on dystocia and stillbirths declined with parity. Effects of inbreeding were small, especially in later parities, but were consistently unfavorable.

Key words: threshold model, inbreeding depression, dystocia, stillbirth

Received April 13, 2005.

Accepted August 16, 2005.

Corresponding author: vadamec@mendelu.cz

\section{INTRODUCTION}

Calving difficulty (CD) is an important problem in Holstein cattle; about one birth of every 5 to firstparity dams "need assistance" (Meyer et al., 2001). Intensive selection for high yields and improved type has reduced effective population sizes and increased average inbreeding coefficients within all pure breeds. Average inbreeding coefficients for females of different dairy breeds born in 2004 range from 5.0\% for Holsteins to $7.1 \%$ for Jerseys (Animal Improvement Programs Laboratory, 2005). These developments contribute to increased interest in crossbreeding in the US. A recent survey of dairy farmers who use crossbreeding indicated that improved calving ease, health, fertility, and longevity were primary objectives for almost all respondents (Weigel and Barlass, 2003). If inbreeding is a causative factor in dystocia, then heterosis from crossbreeding would be expected to be beneficial. Inbreeding does affect other aspects of reproduction, such as interval to estrus and number of services per gestation (Young et al., 1969). Hodges et al. (1979) found no effects of inbreeding on calving interval, but later work by Smith et al. (1998) showed an increase of $5 \mathrm{~d}$ in age at first calving and a 3.3-d extension of calving interval in young cows with $12.5 \%$ inbreeding. Thompson et al. (2000) reported that inbreeding affected phenotypic performance for reproduction in young animals, but that effects moderated in mature animals.

Calving difficulty has been implicated as the major cause of stillbirth (SB), yet about 50\% of stillborn calves are from unassisted births (Philipsson, 1996). Ron et al. (1986) found that genetic correlations between SB and CD declined with parity. Luo et al. (1999) and Steinbock et al. (2003) reported moderate negative correlations between direct and maternal effects. Steinbock et al. (2003) and Hansen et al. (2004a) recommended that both direct and maternal effects on SB be considered in breeding programs or used to screen extreme genotypes. 
Calving difficulty is affected by maternal and direct genetic components. Weller and Gianola (1989) reported that service sire effects were more important for CD than were sire of cow effects. Weller et al. (1988) reported larger genetic differences for CD between first-parity mothers than between older cows. Boettcher et al. (2000) recommend that CD in heifers and cows be treated as separate, correlated traits. Genetic evaluations for CD have been available for Holstein sires in the US for many years, but were recently (February 2005) introduced for Brown Swiss. Sire evaluations for CD were unnecessary in Jerseys because of small differences between sires (Cole et al., 2005).

Both maternal and fetal inbreeding may affect CD. Young et al. (1969) reported a decline in birth weights of $0.11 \mathrm{~kg} / 1 \%$ increase in fetal inbreeding. Smaller calves could be born more easily, yet may be more prone to SB. Meyer et al. (2001) reported that the effect of calf sex on SB varied by parity; smaller (heifer) calves were born more easily and were less prone to SB in first parity but were more susceptible to SB in later parities. Effects of inbreeding in the dam or the fetus on CD and SB may not be consistent across parity and sex of calf combinations.

Maternal inbreeding has been shown to reduce growth rates of heifers, potentially increasing CD and SB in first-parity births. Young et al. (1969) reported inbreeding depression of 2-yr weights of $1.45 \mathrm{~kg} / 1 \%$ increase in inbreeding. Compensatory growth could offset such effects as cows mature. We chose to address inbreeding in the dam in this study. Our objective was to estimate maternal inbreeding depression for CD and SB in different parities using binomial expressions of each trait and a liability threshold model as described by Gianola and Foulley (1983).

\section{MATERIALS AND METHODS}

\section{Data}

Data were provided by Iowa State University and were recorded by dairy producers at the farm using National Association of Animal Breeders scoring systems for CD (Berger, 1994). Stillbirth was also recorded as 0 for alive and 1 for dead by $48 \mathrm{~h}$. Data were from Holstein dams born between 1985 and 1995. Only data from 120,434 registered cows (218,213 births) were used to ensure pedigree completeness for estimation of inbreeding coefficients (Cassell et al., 2003). Producers assigned scores for CD of $1=$ no problem, $2=$ slight problem, $3=$ needed assistance, $4=$ considerable force, and $5=$ extreme difficulty.
Table 1 shows the distribution of CD scores for registered cows in the original data. The data included about $75 \%$ as many first-parity births as second-parity births. Reasons for this pattern of reporting are not known, but the data collection system did rely on voluntary cooperation of producers to record and report CD and SB. Lactation data reported through production recoding systems are almost always available on more first-parity cows than second-parity cows because of complete herd recording and culling of some cows following first lactation. Those factors did not affect recording of $\mathrm{CD}$ and $\mathrm{SB}$ in the same way.

Dystocia scores of $\geq 3$ were more common for younger than for older cows. Only $5.2 \%$ of female births to cows in second and later parities were coded $\geq 3$. Calving difficulty scores from first, second, and third parities were used for this study; later parities were discarded. Calving difficulty scores were recoded with scores of 1 and 2 assigned a 0 and scores 3,4 , and 5 assigned a 1 . Meyer et al. (2001) reported $>28 \%$ dystocia in firstparity births in US Holsteins, in which dystocia was defined as any birth other than those with "no assistance." If scores of $\geq 2$ are assumed to indicate assistance needed, our data included $32.8 \%$ dystocia in firstparity births.

Pedigree data from the Animal Improvement Programs Laboratory (ARS, Beltsville, MD) were used to calculate inbreeding coefficients with the procedures of Golden et al. (1995) in the Animal Breeder's Tool Kit. Five generations of pedigree information, if available, were retrieved from a pedigree base of 1960. Average inbreeding was $2.54 \pm 2.42 \%$ for all cows in the study. Animal Improvement Programs Laboratory (2005) reported that average inbreeding in Holstein females increased from 1.2 to $3.5 \%$ for births in 1985 vs. 1995, which corresponds to the birth years of dams in this study. An evaluation of pedigree completeness (Cassell et al., 2003) showed an average of $93.1 \%$ of pedigree information present for cows in the study. Prolonged generation intervals, a pedigree base of 1960, and use of a 5-generation standard for pedigree completeness in the procedure accounted for missing pedigree information in these registered cows.

\section{Statistical Models and Analysis}

The threshold model application of Multiple Trait Gibbs Sampler for Animal Models (MTGSAM) by Van Tassell and Van Vleck $(1995,1996)$ was used to estimate posterior densities for thresholds, random variance components, and fixed effects as shown in the following model:

$$
\mathrm{Y}=\mathrm{X} \beta+\mathrm{F} \gamma+\mathrm{Z}_{\mathrm{h}} \mathrm{h}+\mathrm{Z}_{\mathrm{S}} \mathrm{s}+\mathrm{Z}_{\mathrm{c}} \mathrm{c}+\varepsilon
$$


Table 1. Distribution of original data for calving difficulty scores in registered Holsteins by parity

\begin{tabular}{|c|c|c|c|c|c|}
\hline \multirow[b]{2}{*}{ Parity } & \multicolumn{5}{|c|}{ Dystocia score } \\
\hline & 1 & 2 & 3 & 4 & 5 \\
\hline \multicolumn{6}{|l|}{1} \\
\hline \multicolumn{6}{|l|}{ Male births } \\
\hline no. & 14,360 & 2848 & 3696 & 1756 & 963 \\
\hline$\%$ scores & 60.8 & 12.1 & 15.6 & 7.4 & 4.1 \\
\hline \multicolumn{6}{|l|}{ Female births } \\
\hline no. & 17,634 & 2791 & 2437 & 804 & 326 \\
\hline$\%$ scores & 73.5 & 11.6 & 10.2 & 3.3 & 1.4 \\
\hline \multicolumn{6}{|l|}{2} \\
\hline \multicolumn{6}{|l|}{ Male births } \\
\hline no. & 27,226 & 2317 & 1978 & 774 & 475 \\
\hline$\%$ scores & 83.1 & 7.1 & 6.0 & 2.4 & 1.4 \\
\hline \multicolumn{6}{|l|}{ Female births } \\
\hline no. & 26,548 & 1673 & 1091 & 284 & 148 \\
\hline$\%$ scores & 89.2 & 5.6 & 3.7 & 1.0 & 0.5 \\
\hline \multicolumn{6}{|l|}{$\geq 3^{1}$} \\
\hline \multicolumn{6}{|l|}{ Male births } \\
\hline$\%$ scores & 84.6 & 6.4 & 5.8 & 2.0 & 1.2 \\
\hline \multicolumn{6}{|l|}{ Female births } \\
\hline no. & 45,944 & 2799 & 1913 & 450 & 291 \\
\hline$\%$ scores & 89.4 & 5.4 & 3.7 & 0.9 & 0.6 \\
\hline
\end{tabular}

${ }^{1}$ Only third-parity results were used for analysis.

where $\mathbf{Y}$ is a vector of underlying liabilities for $\mathrm{CD}$ in parity 1,2 , or 3 in separate analyses, where CD expressed in binary form as easy (0) or difficult (1). The same model was used to evaluate SB, coded as 0 for alive at $48 \mathrm{~h}$, and 1 otherwise. Matrices $\mathbf{X}, \mathbf{F}, \mathbf{Z}_{\mathbf{h}}$, $\mathbf{Z}_{\mathbf{s}}$, and $\mathbf{Z}_{\mathbf{c}}$ are the corresponding design matrices associating individual effects to the records. $\boldsymbol{\beta}$ is a vector of two parameters for sex of the calf (fixed), $\gamma$ is a scalar value of the solution for maternal inbreeding (fixed), $\mathbf{h}$ is a vector of herd-year-season (HYS) of calving levels (random), $\mathbf{s}$ is a vector of sire of the calf (service sire) transmitting abilities (random), $\mathbf{c}$ is a vector of sire of the cow (maternal grandsire) transmitting abilities (random), and $\varepsilon$ is a vector of residual effects (random).

Separate data sets were created for parities 1,2 , and 3 . We reduced the size of original data sets by using all data within a subset of herds randomly chosen from those with at least 5 observations in all HYS. The intended size of data sets was about 30,000 records for first and second parities where more data were available than could be analyzed with the computing power available. Fewer third-parity records were available and data sets analyzed included about 15,000 records. We combined adjacent HYS as necessary to avoid the "extreme category problem" first described by Harville and Mee (1984) and again by Misztal et al. (1989), such that some variation in CD existed within each HYS. Those few HYS with no variation in $\mathrm{CD}$ were discarded. Combinations of and/ or elimination of HYS were more frequently applied in later parities where incidence of difficult births was low.

Two independent chains of Gibbs samples were generated for each parity data set (Van Tassell et al., 1998) using heritability of $15 \%$ and HYS variance of $10 \%$ of total variation as starting values. Following the recommendations of Raftery and Lewis (1991), 200,000 to 300,000 samples were generated for each chain; the first 5,000 samples were discarded for burnin. A primary thinning rate of one sample in 50 was used to obtain initial lag correlations between samples using the Lagcor utility of Van Tassell and Van Vleck (1995). Additional thinning was subsequently applied to produce 100 to 130 (Table 2) independent samples from each chain to estimate posterior means (Boettcher and Wang, 2000). The thinned samples represented between one in 750 samples and one in 5900 samples from the complete Gibbs chains. Results from the 2 independent chains were combined by the weighted averaging procedures of Van Tassell et al. (1998) and Boettcher et al. (2000).

Estimates of fixed effects and solutions for levels of random effects were expressed in units of residual standard deviations by the MTGSAM procedure. These were converted to probabilities of CD using procedures of Sorensen et al. (1995). We calculated separate probabilities for each parity data set and combination of sex of calf by maternal inbreeding. Effects of inbreeding up to $40 \%$, the limit of inbreeding in the data, were determined. Estimates of inbreeding depression per $1 \%$ increase in inbreeding were made for 
Table 2. Posterior distributions of dispersion parameters for calving difficulty by parity, expressed in units of the unobserved (threshold) scale

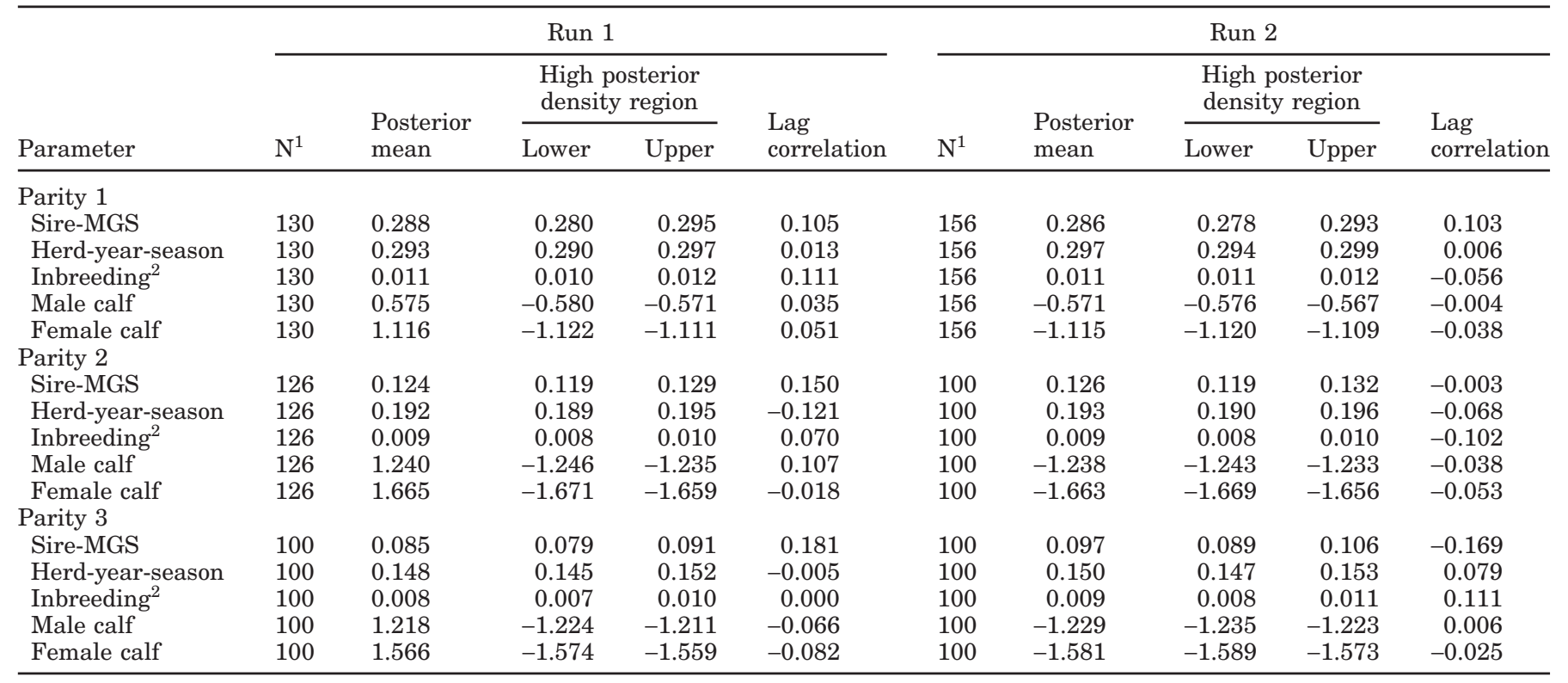

${ }^{1}$ Number of samples used to estimate posterior mean, representing between 1 sample in 750 and 1 sample in 5,900 of the original Gibbs chains.

${ }^{2}$ Inbreeding depression per $1 \%$ increase in inbreeding.

each sex of calf using the difference in probabilities of $\mathrm{CD}$ or SB at 0 and $40 \%$ inbreeding.

\section{RESULTS}

Posterior distributions of Gibbs sampling parameter estimates from MTGSAM for CD are presented in Table 2. It was necessary to calculate long Gibbs sample chains and to use extreme thinning to reduce the lag correlations between samples. We attribute this characteristic of the analysis to mild inbreeding and the low frequency of CD (and subsequently for SB), especially in later parities. The lag correlations from final samples were similar to Hoeschele and Tier (1995). Van Tassell et al. (1998) reported that large autocorrelations still allow for unbiased estimation of the posterior distribution, although variances may be underestimated. Terms of major interest were fixed effects of inbreeding and sex of calf by parity, rather than genetic or HYS variance components. Heritability was not estimated. Lag correlations between samples were usually \pm 0.10 or less, but ranged from -0.169 to 0.181 . Posterior means for run 1 and run 2 were very close. Posterior means in Table 2 are expressed in units of the unobserved, threshold scale. These were converted to probabilities of CD as shown in Table 3.

Table 3 shows the observed and predicted probabilities of CD for male or female births for parities 1,2 , and 3. Observed CD in the data ranged from $28 \%$ for male calves born to first-parity females to $6 \%$ for female calves born to second-parity dams. Our incidence rates were higher than reported by Hansen et al. (2004b), who reported $11.2 \%$ difficult births across sexes on a 4-point scale in Danish Holsteins. Calving difficulty in our data was similar to Meyer et al. (2001), who reported over $28 \%$ dystocia in US Holsteins, where dystocia was defined as "assistance of any kind."

Average inbreeding of dams in the different parity groups appears in Table 3 along with estimates of effects of inbreeding in the dam on CD. Inbreeding among dams was mild for all data sets but was slightly higher in younger cows, $3.23 \%$ for first-parity dams vs. 2.93 and $2.59 \%$ for second- and third-parity dams. This result is consistent with the trends in inbreeding reported by Animal Improvement Programs Laboratory (2005). Predicted probabilities of CD for 0 and $3 \%$ inbreeding in the dam are shown, along with estimated change in probability per $1 \%$ increase in inbreeding as described earlier. Predicted incidence of dystocia using fixed effects of sex of calf and inbreeding agreed well with observed frequencies. For instance, predicted dystocia among first-parity dams with $3 \%$ inbreeding giving birth to male calves was $29.5 \%$; the observed value was $28.4 \%$.

Many factors in addition to inbreeding affect CD. The predicted probability of dystocia in noninbred, first-parity dams was $28 \%$ when giving birth to male calves and $16 \%$ when giving birth to female calves. In 
Table 3. Expected probabilities of difficult calving for male or female calf births and cow parities one through three as affected by varying levels of maternal inbreeding

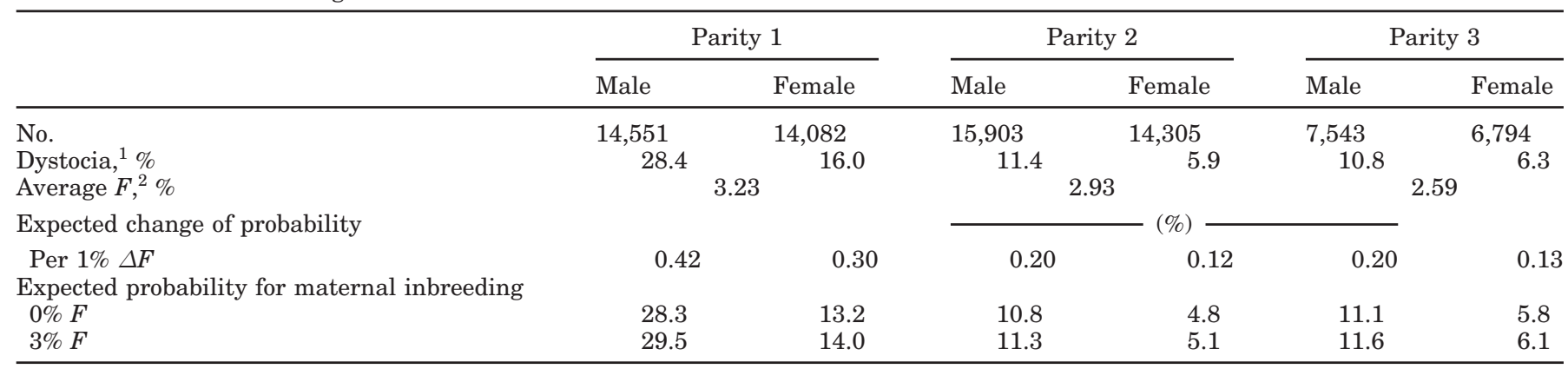

${ }^{1}$ Observed proportion of difficult calvings from respective datasets.

${ }^{2}$ Average maternal inbreeding for cows in each data set.

noninbred second-parity dams, expected probability of CD is 10.8 and $4.8 \%$ for male and female calves, respectively. Probabilities of CD considering 3\% inbreeding are only slightly larger than the noninbred probabilities.

Table 4 shows the effects of inbreeding on SB using the same approaches used for CD. Again, we used long Gibbs sample chains and extreme thinning to reduce the lag correlations between samples. Posterior means for some of the random effects in the model in runs 1 and 2 were different. Our interests were in solutions for fixed effects of calf sex and inbreeding, which did give similar results from runs 1 to 2 . The same model was used for analysis of SB and CD, but some of the terms might have been inappropriate for SB. Some important information might have been omitted from the model. For instance, the size of the calf born to older dams may be critical to early survival. We did not have access to birth weights of calves in these data. The incidence of SB was lower than for dystocia in all parities with a maximum value of $13.4 \%$ for male calves born to first-parity dams to low values of 5.5 and $6.7 \%$ SB for births of either sex in second and third parities.

Effects of inbreeding on SB were small, consistently unfavorable, larger for males than females, and declined as dams matured. Probabilities of SB in first parity increased $0.25 \%$ (male) and $0.20 \%$ (female) $/ 1 \%$ increase in inbreeding. Effects of inbreeding on SB declined in second-parity births; a $1 \%$ increase in inbreeding resulted in an increase of $0.05 \%$ in incidence of SB for males and $0.04 \%$ increase of SB for female calves. These effects were only $20 \%$ of the estimates from first parity. Estimates of inbreeding depression from third-parity births were very near zero. Predicted frequencies for SB were about $80 \%$ of observed frequencies for first-parity births, very close to observed frequencies in second-parity births, but only about $44 \%$ of observed frequencies for third-parity births.

\section{DISCUSSION}

Phenotypic trends in CD and SB reported by Hansen et al. (2004b) document more frequent dystocia and

Table 4. Expected probabilities of stillbirth by $48 \mathrm{~h}$ postpartum for male or female births and cow parities one through three as affected by varying levels of maternal inbreeding

\begin{tabular}{|c|c|c|c|c|c|c|}
\hline & \multicolumn{2}{|c|}{ Parity 1} & \multicolumn{2}{|c|}{ Parity 2} & \multicolumn{2}{|c|}{ Parity 3} \\
\hline No. & 14,675 & 14,187 & 16,465 & 14,784 & 7,724 & 6,942 \\
\hline Average $F, 2 \%$ & \multicolumn{2}{|c|}{3.24} & \multicolumn{2}{|c|}{2.92} & \multicolumn{2}{|c|}{2.62} \\
\hline \multicolumn{7}{|l|}{ Expected change of probability of calf deaths } \\
\hline $\begin{array}{l}\text { Per } 1 \% F \\
\text { Expected probability for maternal inbreeding }\end{array}$ & 0.25 & 0.20 & 0.05 & 0.04 & 0.005 & 0.005 \\
\hline $3 \% \mathrm{~F}$ & 11.0 & 7.8 & 6.8 & 5.5 & 3.0 & 2.7 \\
\hline
\end{tabular}

${ }^{1}$ Observed proportion of calf mortality from respective datasets.

${ }^{2}$ Average maternal inbreeding for cows in each data set. 
SB problems in current Holstein populations than existed in the data used for this study. Meyer et al. (2001) reported increases in first-parity SB from 9.5 to $13.2 \%$ for dams born between 1985 and 1995 using much of the same data as in this study. Holstein cows born in the US in 2004 averaged 5.0\% inbreeding (Animal Improvement Programs Laboratory, 2005), well above the average of 2.6 to $3.2 \%$ in these data. An inbreeding study of current data could show more dramatic effects of inbreeding on CD and SB than we report here. Nonetheless, our results document an increase in CD and SB during the period studied as a consequence of increased inbreeding in the dam.

Results for effects of inbreeding on SB should be interpreted with some caution. Predicted results for SB in second parity regenerated the original frequencies found in the data, and predicted incidence for firstparity births were about $80 \%$ of the observed frequencies. Predicted incidence of SB in third parity was only $44 \%$ of observed frequency. Data were contributed voluntarily by producers, and education efforts of the era emphasized recording of dystocia and SB from younger cows. It is possible that neither CD nor SB was expected, considered important, or recorded and reported rigorously in mature Holstein dams. Herd management practices that ignored potential calving problems in older cows that would have been more carefully monitored in younger cows could cause SB in an older cow to be a somewhat different trait than for younger cows. Our statistical model accounted for effects of HYS of birth of the calf, genetic effects arising from sires and maternal grandsire, sex of the calf, and inbreeding of the dam and was applied to separate data sets for each of the first 3 parities. Records of SB in third-parity dams were only about one-half as numerous as for first or second parity. Both the model used and the data structure likely contributed to underestimation of the observed frequencies of SB in third-parity dams.

All estimates of effects of inbreeding on CD were unfavorable, but small. Greatest effects were for births to male calves in first parity. Effects of inbreeding were smaller for female calves, and all effects of inbreeding declined in second and third parities. Compensatory growth in maturing animals appears to mediate effects of maternal inbreeding, though BW would be helpful to verify such a conclusion. More inbred dams may, through effects of uterine environment, give birth to smaller calves, whether those calves are inbred or not. Effects of inbreeding on CD or SB may be suppressed by the depression of growth in newborns of inbred dams. We did not have access to birth weights to test such a hypothesis. Our findings indicate that inbreeding is not the major cause of CD or SB in Holsteins, although efforts to reduce inbreeding would have favorable effects on both problems.

The Jersey breed does not experience problems with CD (Cole et al., 2005), but inbreeding is greater in Jerseys than in Holsteins. The authors are not aware of documentation of SB in Jerseys, perhaps because $\mathrm{CD}$ has not been thoroughly studied in the breed. Jerseys are documented to deliver calves more quickly than Swedish Friesians (Berglund et al., 1987). They may dilate more fully or more rapidly, contract more strongly or more persistently, or perhaps the size and shape of a Jersey fetus is more conducive to rapid, nontraumatic delivery. Jersey calves are dramatically smaller than Holsteins. Cassell et al. (2005) reported birth weights of $38.5 \mathrm{~kg}$ for purebred Holstein calves and $22.5 \mathrm{~kg}$ for purebred Jersey calves born in the same herd in a current crossbreeding study. Genes responsible for the birth process in Jerseys appear to be different or act differently from the genes involved in parturition in the Holstein breed.

The influence of Holstein-Friesian genetics on CD and SB in Denmark and Sweden is well documented. Hansen et al. (2004a) found that CD and SB rates increased with the percentage of Holstein-Friesian genes in both calf and dam, but that heterosis (with Danish Black and White foundation females) was not significant. Steinbock et al. (2003) reported an increase of SB concurrent with an infusion of Holstein-Friesian genes into Swedish Holstein populations. The additive effects of the imported genes overwhelmed any beneficial heterosis that might have existed from crosses of North American and Swedish Holstein strains. In light of these findings, relatively small effects of inbreeding on $\mathrm{CD}$ and SB should be expected. Calving difficulty and SB appear be controlled primarily by additive genetic effects, with small or nonexistent effects of heterosis.

Hansen et al. (2004b) reported unfavorable trends in $\mathrm{CD}, \mathrm{SB}$, and calf size concurrent with an increase in frequency of North American Holstein-Friesian genes in Danish Holsteins. Those researchers found evidence of unfavorable maternal effects for SB, but favorable maternal effects for CD. Thus, calf size contributed to, but was not entirely responsible for increases in CD and SB. This study eliminated the possible effects of a recently discovered genetic defect of North American Holstein origin, complex vertebral malformation, on increases in SB through examination of progeny groups of known carrier, possible carrier, and known noncarrier bulls. Complex vertebral malformation has been shown by Nielsen et al. (2003) to terminate gestation in most cases prior to $260 \mathrm{~d}$, well before expression of CD or SB. 


\section{CONCLUSIONS}

These data were characterized by mild inbreeding. Calving difficulty and SB are relatively infrequent events in later parities, suggesting that effects of inbreeding would be smaller for later parities, as was observed in the results. Effects of inbreeding in the dam on CD and SB were consistently unfavorable. Largest effects were in first-parity births. The effect of inbreeding on CD from second-parity births was about $50 \%$ of that for first parity. Inbreeding in the dam may exert its effect on CD and SB by reducing growth rates in heifers, as compensatory growth in the dam might have moderated effects of inbreeding in later parities. Average inbreeding in Holstein dams increased from 1.5 to $3.7 \%$ during the years covered by this study (Animal Improvement Programs Laboratory, 2005). Our estimates of inbreeding depression predicted an increase in probability of CD in firstparity dams of 0.92 and $0.66 \%$ for males and females because of increased inbreeding for the period. For $\mathrm{SB}$, predicted increases were 0.55 and $0.44 \%$. Such increases, considered alone, are not justification for major changes in breeding programs. However, they add to a litany of undesirable consequences of inbreeding in Holsteins documented in recent years.

\section{ACKNOWLEDGMENTS}

The authors express gratitude to Jeff Berger of Iowa State University for calving ease and SB data, to the Animal Improvement Programs Laboratory (ARSUSDA, Beltsville, MD) for computing resources and pedigrees, and to Curt Van Tassell for assistance with MTGSAM programs.

\section{REFERENCES}

Animal Improvement Programs Laboratory. 2005. Inbreeding coefficients for Holstein Cows. Available: http://aipl.arsusda.gov/dynamic/inbrd/current/kindx.html Accessed Jun. 27, 2005.

Berger, J. P. 1994. Genetic prediction for calving ease in the United States: Data, models and use by the dairy industry. J. Dairy Sci. 76:1146-1153.

Berglund, B., J. Philipsson, and O. Danell. 1987. External signs of preparation for claving and course of parturition in Swedish dairy cattle breeds. Anim. Reprod. Sci. 15:61-79.

Boettcher, P. J., M. Luo, L. Schaeffer, and J. Dekkers. 2000. Estimates of genetic parameters for calving ease in first and second lactations. Report to Technical Committee of the Genetic Evaluation Board. Available: http://cgil.uoguelph.ca/dcbgc/agenda 0007/gebce12.htm Accessed Apr. 7, 2005.

Boettcher, P. J., and Y. Wang. 2000. Estimates of heritabilities for defective type characteristics of Canadian Holsteins. Report to the technical committee of the Dairy Genetic Evaluation Board. September 2000. Available: http://cgil.uoguelph.ca/dcbgc/ agenda0007/defgeb.htm Accessed Apr. 7, 2005.

Cassell, B. G., V. Adamec, and R. E. Pearson. 2003. Effect of incomplete pedigrees on estimates of inbreeding and inbreeding de- pression for days to first service and summit milk yield in Holsteins and Jerseys. J. Dairy Sci. 86:2967-2976.

Cassell, B. G., A. J. McAllister, R. L. Nebel, S. Franklin, K. E. Getzewich, J. Ware, J. Cornwell, and R. E. Pearson. 2005. Birth weights, mortality, and dystocia in Holsteins, Jerseys, and their reciprocal crosses in the Virginia Tech - Kentucky crossbreeding project. J. Dairy Sci. 88(Suppl. 1):92. (Abstr.)

Cole, J. B., R. C. Goodling, Jr., G. R. Wiggans, and P. M. VanRaden. 2005. Genetic evaluation of calving ease for Brown Swiss and Jersey bulls from purebred and crossbred calvings. J. Dairy Sci. 88:1529-1539.

Gianola, D., and J. L. Foulley. 1983. Sire evaluation for ordered categorical data with a threshold model. Genet. Sel. Evol. 15:201-224.

Golden, B. L., W. M. Snelling, and C. H. Mallinckrodt. 1995. Animal Breeder's Tool Kit 2.0. User's Guide and Reference Manual. Dep. Anim. Sci., Colorado State Univ., Fort Collins.

Hansen, M., M. S. Lund, J. Pedersen, and L. G. Christensen. 2004a. Genetic parameters for stillbirth in Danish Holstein cows using a Bayesian threshold model. J. Dairy Sci. 87:706-716.

Hansen, M., I. Misztal, M. S. Lund, J. Pedersen, and L. G. Christensen. 2004b. Undesired phenotypic and genetic trend for stillbirth in Danish Holsteins. J. Dairy Sci. 87:1477-1486.

Harville, D. A., and R. W. Mee. 1984. A mixed-model procedure for analyzing ordered categorical data. Biometrics 40:393-408.

Hodges, J., L. Tannen, B. J. McGillivray, P. G. Hiley, and S. Ellis. 1979. Inbreeding levels and their effect on milk, fat and calving interval in Holstein-Friesian cattle. Can. J. Anim. Sci. 59:153-158.

Hoeschele, I., and B. Tier. 1995. Estimation of variance components of threshold characters by marginal posterior modes and means via Gibbs sampling. Genet. Sel. Evol. 27:519-540.

Luo, M. F., P. J. Boettcher, L. R. Schaeffer, and J. C. M. Dekkers. 1999. Estimation of genetic parameters of calving ease and stillbirth by using a threshold Bayesian model. Technical Report to the Genetic Evaluation Board. September. Available: http:// cgil.uoguelph.ca/pub/pbpapers/gebtc99-3.htm Accessed Aug. 8, 2001.

Meyer, C. L., P. J. Berger, K. J. Koehler, J. R. Thompson, and C. G. Sattler. 2001. Phenotypic trends in incidence of stillbirth for Holsteins in the United States. J. Dairy Sci. 84:515-523.

Misztal, I., D. Gianola, and J. L. Foulley. 1989. Computing aspects of a nonlinear method of sire evaluation for categorical traits. J. Dairy Sci. 72:1557-1568.

Nielsen, U. S., G. P. Aamand, O. Andersen, C. Bendixen, V. H. Nielsen, and J. S. Agerholm. 2003. Effects of complex vertebral malformation on fertility traits in Holstein cattle. Livest. Prod. Sci. 79:233-238.

Philipsson, J. 1996. Strategies to reduce problems in calving performance and stillbirths by selection and differential use of bulls. Proc. Intl. Workshop on Genet. Improvement of Functional Traits in Cattle, Gemloux, Belgium. Interbull Bull. 12:65-71.

Raftery, A. E., and S. M. Lewis. 1991. How many iterations in the Gibbs Sampler? Available: http://www.stat.washington.edu/ www/research/online/1994/raftery-lewis2.ps Accessed Apr. 7, 2005.

Ron, M., R. Bar-Anan, and J. I. Weller. 1986. Sire and maternal grandsire effects on calving difficulty and stillbirth in Israeli Holsteins. J. Dairy Sci. 69:243-247.

Smith, L. A., B. G. Cassell, and R. E. Pearson. 1998. The effects of inbreeding on the lifetime performance of dairy cattle. J. Dairy Sci. 81:2729-2737.

Sorensen, D. A., S. Andersen, D. Gianola, and I. Korsgaard. 1995. Bayesian inference in threshold models using Gibbs sampling. Genet. Sel. Evol. 27:229-249.

Steinbock, L., A. Näsholm, B. Berglund, K. Johansson, and J. Philipsson. 2003. Genetic effects on stillbirths and calving difficulty in Swedish Holsteins at first and second calving. J. Dairy Sci. 86:2228-2235.

Thompson, J. R., R. W. Everett, and N. L. Hammerschmidt. 2000. Effects of inbreeding on production and survival in Holsteins. J. Dairy Sci. 83:1856-1864. 
Van Tassell, C. P., and L. D. Van Vleck. 1995. A Manual for Use of MTGSAM. A Set of Fortran Programs to Apply Gibbs Sampling to Animal Models for Variance Component Estimation. Univ. Nebraska, Lincoln.

Van Tassell, C. P., and L. D. Van Vleck. 1996. Multiple-trait Gibbs sampler for animal models: Flexible programs for Bayesian and likelihood based (co)variance component inference. J. Anim. Sci. 74:2586-2597.

Van Tassell, C. P., L. D. Van Vleck, and K. E. Gregory. 1998. Bayesian analysis of twinning and ovulation rates using a multipletrait threshold model and Gibbs sampling. J. Anim. Sci. 76:2048-2061.
Weigel, K. A., and K. A. Barlass. 2003. Results of a producer survey regarding crossbreeding on US dairy farms. J. Dairy Sci. $86: 4148-4154$.

Weller, J. I., and D. Gianola. 1989. Models for genetic analysis of dystocia and stillbirth. J. Dairy Sci. 72:2633-2643.

Weller, J. I., I. Misztal, and D. Gianola. 1988. Genetic analysis of dystocia and stillbirth in Israeli Holsteins by threshold and linear models. J. Dairy Sci. 71:2491-2501.

Young, C. W., W. J. Tyler, A. E. Freeman, H. H. Voelker, L. D. McGilliard, and T. M. Ludwick. 1969. Inbreeding investigations with dairy cattle in the North Central region of the United States. North Central Reg. Res. Publ. 191. Minnesota Agric. Exp. Stn. Tech. Bull. 266. Univ. Minnesota, St. Paul. 